\title{
Nosocomial bacterial infections and their antimicrobial susceptibility patterns among patients in Ugandan intensive care units: a cross sectional study
}

Peter Agaba*, Janat Tumukunde, J. V. B. Tindimwebwa and Arthur Kwizera

\begin{abstract}
Background: The intensive care unit (ICU) admits critically ill patients requiring advanced airway, respiratory, cardiac and renal support. Despite the highly-specialized interventions, the mortality and morbidity is still high due to a number of reasons including nosocomial infections, which are the most likely complications in hospitalized patients with the rates being highest among ICU patients.

Methods: In this cross-sectional study of 111 adult patients admitted to 2 of the ICUs in Uganda, we set out to describe the commonest bacterial infections, their antimicrobial susceptibility patterns and factors associated with development of a nosocomial infection.

Results: Klebsiella pneumoniae (30\%), Acinetobacter species (22\%) and Staphylococcus aureus (14\%) were the most frequently isolated bacteria. The prevalence of multidrug resistant bacterial species was 58\%; 50\% Escherichia coli and 33.3\% Klebsiella pneumoniae were extended spectrum beta lactamase or AmpC beta lactamase producers and 9.1\% Acinetobacter species were extensive drug resistant. Imipenem was the antibiotic with the highest susceptibility rates across most bacterial species. Institution of ventilator support (P 0.003) and severe traumatic brain injury (P 0.035) were highly associated with the development of nosocomial infections.

Conclusion: Due to the high prevalence of multi drug resistant (MDR) and extensive drug resistant bacterial species, there is a need for development of strong policies on antibiotic stewardship, antimicrobial surveillance and infection control to help guide empirical antibiotic therapy and prevent the spread of MDR bacteria and antibiotic drug resistance.
\end{abstract}

Keywords: Drug resistance, Intensive care unit, Nosocomial infections, Mechanical ventilation, Traumatic brain injury

\section{Background}

Nosocomial infections (NIs) are defined as hospital acquired infection developing at least $48-72 \mathrm{~h}$ after admission [1]. They are the commonest complications affecting hospitalized patients but are more frequent in intensive care units [2] where outbreaks often originate [3].

*Correspondence: pagaba@chs.mak.ac.ug Department of Anaesthesia, College of Health Sciences, Makerere University, P. O. Box 7072, Kampala, Uganda
Three types of infection account for more than $60 \%$ of all nosocomial infections: pneumonia (usually ventilator-associated), urinary tract infection (usually catheterassociated) and primary bloodstream infection (usually associated with the use of an intravascular device) [4]. Antibiotic resistant Gram-positive or negative bacteria including Staphylococci, a wide variety of Enterobacteriaceae, Pseudomonas species, Acinetobacter species. account for up to $70 \%$ of the nosocomial infections in the ICU patients [5-8].

Five to ten percent of patients admitted to acute care hospitals acquire one or more infections, and the risks 
have steadily increased during recent decades $[9,10]$. Intensive care units represent only $5-15 \%$ of hospital beds and account for $10-25 \%$ of healthcare costs, corresponding to $1-2 \%$ of the gross national product of the United States [6]. A World Health Organization (WHO) systematic review and meta-analysis showed health-careassociated infection density in adult intensive-care units in developing countries was 47.9 per 1000 patient-days (95\% CI 36.7-59.1), at least three times as high as densities reported from the USA. In Canada, Zhanel et al., between 1 September 2005 and 30 June 2006, collected 4180 isolates recovered from clinical specimens from patients in 19 intensive care units and found Staphylococcus aureus (methicillin sensitive $S$. aureus and methicillin resistant S. aureus, MRSA), Escherichia coli, Pseudomonas aeruginosa, Haemophilus influenzae, Enterococcus species, Streptococcus pneumoniae, and Klebsiella pneumoniae were the most common isolates [11].

In a study in San Paulo by Carlos Toufen et al. Population sample of 126 patients found the most frequently isolated bacteria to be Enterobacteriaceae (33.8\%), P. aeruginosa (26.4\%), and S. aureus (16.9\%).

In Kenya, at Kenyatta National Hospital intensive care unit, the most frequently isolated organisms included $P$. aeruginosa, Klebsiella, Citrobacter, S. aureus, Staphylococcus pneumoniae, Acinetobacter and E. coli isolated from tracheal aspirate, urine, blood and pus swabs. However, a study done in Mulago Hospital on the prevalence of MRSA among isolates from surgical site infections on the general ward and found a prevalence of $31.5 \%$ [12]. This is comparable with $26.9-29.6 \%$ prevalence reported in USA, Middle East and other selected African hospitals $[13,14]$.

For the development of a NI, two pathophysiologic factors must be present: impaired host defences and colonization by pathogenic or non-pathogenic bacteria [1].

Most nosocomial infections arise from the endogenous bacterial flora although many critically ill patients eventually become colonized with resistant bacterial strains. The urinary tract accounts for up to $35-40 \%$ of nosocomial infections, which are usually due to Gram-negative organisms and are associated with the use of indwelling catheters or urinary obstruction. Wound infections are the second most common cause, accounting for up to $25-30 \%$. Intravascular catheter-related infections are responsible for $5-10 \%$ of intensive care unit infections [15].

Nosocomial pneumonias-the leading cause of death in many intensive care units and the second most common NI, account for another $20-25 \%$ and are often caused by Gram-negative organisms [16]. More than $90 \%$ of pneumonias are acquired while patients are mechanically ventilated [17]. Mechanical ventilation frequently requires tracheal intubation which, allows aspiration of oral and gastrointestinal material and bacteria [18].

Gastro intestinal bacterial overgrowth with translocation into the portal circulation and retrograde colonization of the upper airway from the gastro intestinal tract followed by aspiration are possible mechanisms for entry for these bacteria [19].

Infection is a leading cause of death in the intensive care unit with mortality rates as high as $60 \%$ and twice as much in those patients with a nosocomial infection [20].

The impact of NI on morbidity and mortality is substantial not to mention the effect on increased hospital stay and cost of health care. The increased hospital stay and the need for stronger more expensive drugs mean increased costs for both the patient and the government. This is even more important in resource-limited settings $[21,22]$. Medical legal issues may also arise as patients or relatives may blame the ICU staff or the hospital for causing the infection and demand compensation [23].

The global escalation in both community- and hospitalacquired antimicrobial-resistant bacteria is threatening the ability to effectively treat patients [24]. Treatment options are severely limited because these bacteria frequently display multi drug resistance [16]. It is, therefore, conceivable that patients with serious infections will soon no longer be treatable with currently available antimicrobials.

However, this can be prevented. One study showed that one third of nosocomial infections could be prevented through infection control and watchful programs [25].

Practices as simple as hand hygiene have been shown to be quite effective in reducing the rates of NI $[26,27]$.

Inappropriate empirical antimicrobial therapy is known to adversely affect outcome in severe bacterial infection [28]. Therefore, it is very important for every institution to have local, current microbiological data in order to assess the likely infecting pathogens and the susceptibility patterns. This will facilitate appropriate empirical antimicrobial therapy.

Strict management of antibiotic policies and surveillance programs for resistant organisms, together with infection control procedures, need to be implemented in the ICU and continuously audited.

Although antimicrobial susceptibility patterns are not well documented in Uganda, Anguzu et al in 2007 carried out a study on surgical wound infection that demonstrated resistance to the cheaper more common antibiotics [29]. Therefore, there is a need to develop a national surveillance of antimicrobial resistance patterns.

This study described the common bacterial pathogens and antimicrobial susceptibility pattern among ICU patients in Mulago hospital and International Hospital Kampala. 


\section{Methods}

\section{Study design and setting}

This study was a cross sectional study carried out in the intensive care units of Mulago National referral hospital and International Hospital Kampala.

These units have on average a day and night 1:1.5 nurse patient ratio, a critical care specialist and a resident during the day and an anaesthesia resident at night.

\section{Study population}

All patients newly admitted to intensive care units of Mulago hospital and International Hospital Kampala.

\section{Inclusion criteria}

Admission to the intensive care unit.

\section{Exclusion criteria}

Age less than 18 years and patient's request. If the patient was likely to spend less than $48 \mathrm{~h}$ in the ICU.

\section{Sampling method}

The non-probability consecutive sampling method was used on patients newly admitted to the intensive care unit. Patients were selected as they were admitted to the intensive care unit based on the inclusion criteria.

\section{Consent to participation}

A waiver of consent was obtained from the institutional review board since the study posed minimal risk to the patient. In addition, because majority of patients at admission are incapacitated and unable to provide informed consent it would require locating the next of kin which would introduce delays in collecting the base line sample.

\section{Screening and enrolment}

Using the inclusion and exclusion criteria at admission, patients who were eligible had a study number given and their baseline data such as demographics, reason for admission, referring unit recorded and samples such as blood/ tracheal aspirate/urine for culture and sensitivity collected.

\section{Follow-up}

After 48-72 $\mathrm{h}$ in the intensive care unit, clinically significant samples were taken off for culture and sensitivity. All samples were analysed at a microbiology laboratory.

\section{Sample collection, handling and processing}

Sites selected for blood sampling were swabbed with $70 \%$ alcohol. Five to ten millilitres were collected in bactec bottles, transported to the laboratory and placed in the bactec 9120 instruments. Positive bottles were Gram stained and sub cultured and tested for sensitivity by the microbiologist.
Endo-tracheal aspirates were obtained by suctioning the endo tracheal tube or tracheostomy tubes using a sterile suction catheter and the tip cut off with a sterile surgical blade, placed in sterile container, and sent to the laboratory. The most purulent part of the aspirate was used to inoculate plates of blood, chocolate and MacConkey agar by the laboratory technician. Chocolate and blood plates were incubated in carbon dioxide at 35-37 ${ }^{\circ} \mathrm{C}$ and MacConkey in ambient air for $24 \mathrm{~h}$. Positive cultures that had isolates were identified and sensitivity cultures done.

Mid-stream urine or from a sampling port on an indwelling catheter using an aseptic technique was collected in a sterile container. The samples were used to inoculate blood agar and MacConkey agar, which was then incubated at $35-37{ }^{\circ} \mathrm{C}$ for $18-24 \mathrm{~h}$. Positive cultures were Gram stained and sub cultured and tested for sensitivities.

Pus or wound swabs from ulcers and wounds that were septic were taken off. In the laboratory blood, MacConkey and chocolate agar were inoculated, incubated, and treated as mentioned above.

As recommended by Clinical and Laboratory Standards Institute (CLSI), isolates were screened for extended spectrum beta lactamase ESBL production using the double disc method and MRSA was identified by the use of cefoxitin disc $(30 \mu \mathrm{g})$. Multidrug resistance was defined as an isolate non-susceptible to one or more agents in three antimicrobial classes. Extensive drug resistance was defined as non-susceptible to one or more agents in all but two or less antimicrobial classes [30].

Bactec bottles, catalogue number 442192, were purchased from Becton Dickson and company Maryland USA. Antibiotic discs and agar were purchased from Biolab diagnostic laboratory Zrt Budapest Hungary. The catalogue numbers can be found in the Additional file 1 .

\section{Primary study variables}

1. The five commonest microbes causing nosocomial infections.

2. Sensitivities of these microbes to the commonly used antibiotics in the intensive care unit such as ceftriaxone, imipenem, piperacillin and tazobactam, gentamicin, ampicillin.

\section{Secondary study variable}

1. Characteristics associated with antimicrobial susceptibility patterns such as, age, sex, and length of antibiotic treatment.

\section{Sample size}

Using the formula $\mathrm{N}=\left(\mathrm{Z}^{2} \mathrm{u}\right) / \mathrm{e}^{2}$ to estimate risk with a specified precision, a $95 \%$ confidence interval, and an 
estimated risk of acquiring infection of $0.07^{9}$ and a standard of error of 0.05, sample size calculated was 118 .

\section{Data management and data analysis}

Once ethical approval was obtained the questionnaire was tested on 5 patients and corrections were made after discussions with the research assistants, laboratory technician and the statistician. The pre-tested questionnaires were then used to collect both clinical and laboratory data. The principle investigator and research assistants administered questionnaires while laboratory data was transcribed to the questionnaires from laboratory result forms. Data was checked for completeness and accuracy at the end of every day of data collection.

Data was double entered into Epidata version 3.1 with range, consistency and validity checks embedded to ensure accuracy of data. The data was stored on computer hard drive that is password protected to ensure confidentiality and backed up on separate external hard drives kept in separate locations.

Stata version 12 was used for data analysis. This was a descriptive cohort study therefore; the main analysis was descriptive in nature.

\section{Univariate analysis}

The participant baseline characteristics like age, sex, referral status and admission diagnosis were categorized and presented as categorical variables. These were presented as frequencies and their respective proportions in tables, graphs and text.

The rate of acquiring the commonest microbes in nosocomial infections among ICU patients after admission was assessed using methods of survival analysis while the antimicrobial susceptibility patterns to the commonly used antibiotics was presented as frequencies and proportions.

\section{Bivariate analysis}

The rate of occurrence of nosocomial infection antimicrobial susceptibility among chosen patient characteristics in the ICU was assessed using Poisson regression methods. A p value $<0.05$ was taken as statistically significant.

\section{Quality control}

All research assistants were trained prior to the beginning of the study and during the study.

Questionnaires were tested before the start of actual data collection.

Data cleaning and entry was done on a daily basis and the data was periodically evaluated. All questionnaires were safely stored to enable reference in case of data loss.

\section{Results}

Two hundred and six patients were recruited in a period of 15 months and 111 patients were analysed. The difference was due to loss to follow up and exclusion criteria as shown in Fig. 1.

The largest number of patients admitted into the ICU were under the age of 30 years (39.64\%), $55.86 \%$ were males and $84.68 \%$ were referred from within the hospital (Table 1).

Admitting diagnosis included traumatic brain injury (22\%), respiratory failure (19\%) severe sepsis and septic shock (19\%). Others included cerebral vascular accident (CVA), multiple trauma, haemorrhagic shock and acute kidney injury (AKI) (Fig. 2).

At admission, 82 patients were already receiving antibiotics. $72 \%$ were receiving cephalosporins alone, $11 \%$ were on penicillins alone, $5 \%$ on carbapenems alone, $5 \%$ on a fluoroquinolone alone, $2 \%$ on cephalosporin and metronidazole combined, $2 \%$ on macrolides and quinolone, and the rest equally distributed between macrolides, metronidazole and a combination of a carbapenem and metronidazole.

Only one patient had a culture and sensitivity done before giving antibiotics prior to admission into the ICU and no organism was isolated.

Samples taken off for culture and sensitivity at admission were a tracheal aspirate and blood ( $47 \%$ of the patients), blood and urine ( $2 \%$ of the patients), a tracheal aspirate blood and urine ( $2 \%$ of the patients), blood alone

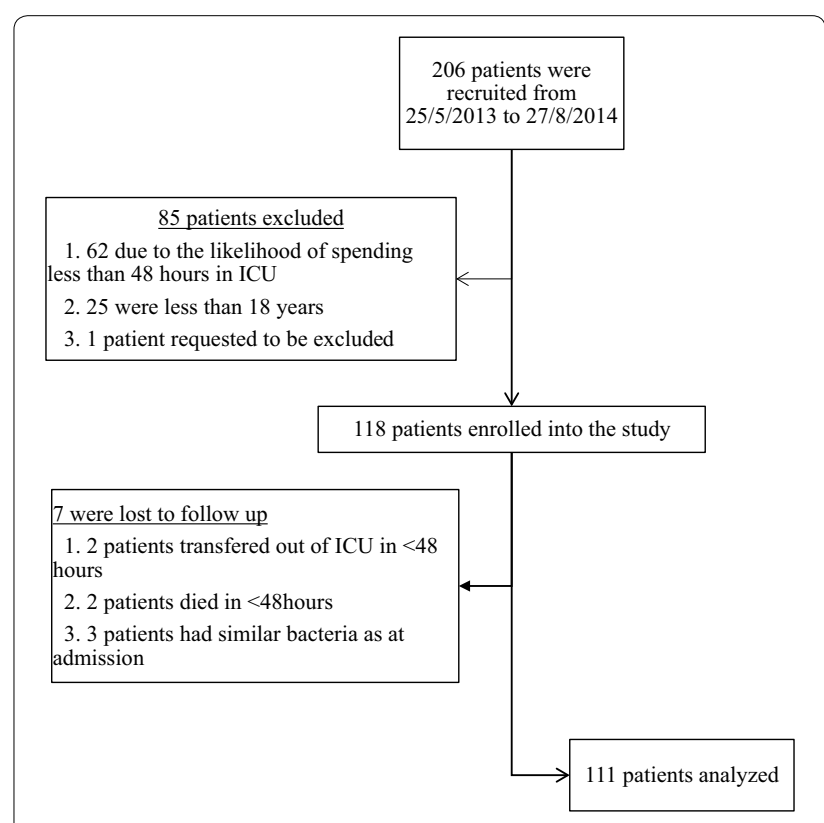

Fig. 1 Study profile: two hundred and six patients were recruited. One hundred and eighteen were enrolled and 7 were lost to follow up. Only 111 patients were included in the analysis 
Table 1 Patient demographics

\begin{tabular}{lc}
\hline & $\mathbf{N}(\%)$ \\
\hline $\begin{array}{l}\text { Age group in years } \\
\leq 30\end{array}$ & $44(39.64)$ \\
$31-40$ & $26(23.42)$ \\
$41-50$ & $9(8.11)$ \\
$51-60$ & $13(11.71)$ \\
$>60$ & $19(17.12)$ \\
Sex & \\
Female & $49(44.14)$ \\
Male & $62(55.86)$ \\
Referring within hospital & \\
No & $17(15.31)$ \\
Yes & $94(84.68)$ \\
\hline
\end{tabular}

(37\% of the patients), tracheal aspirate alone in $12 \%$ of the patients. There were no wound swabs done.

Organisms isolated at admission into the ICU include K. pneumoniae (11.94\%) and E. coli (7.46\%) in the tracheal aspirates, S. aureus (5\%) and coagulase negative S. aureus (2.02\%) in blood. No organisms were isolated in urine (Table 2). Their antibiotic susceptibility patterns are shown in Table 3.

After 48-72 h of admission into the ICU, 32 patients developed a nosocomial infection and a total of 52 isolates were obtained. 20 of these patients grew one organism, 11 grew two organisms and only one patient grew 3 organisms. Samples taken of for analysis were blood and tracheal aspirates alone in 38 and $12 \%$ of the patients respectively, a combination of blood and urine, blood and tracheal aspirate in 1 and $47 \%$ of the patients respectively, and $2 \%$ of patients had blood, urine and tracheal aspirates taken off for analysis.

Organisms isolated (no of isolates) were K. pneumoniae (15), Acinetobacter species (11), S. aureus (7), P. aeruginosa (6), Enterobacter species (5), E coli (2), coagulase negative Staphylococcus (3), Streptococcus viridans (1) and Enterococcus species (1). Their distribution in blood and tracheal is further shown in Table 4.

Antimicrobial susceptibility patterns of the 9 isolated organisms were then analysed according to the samples

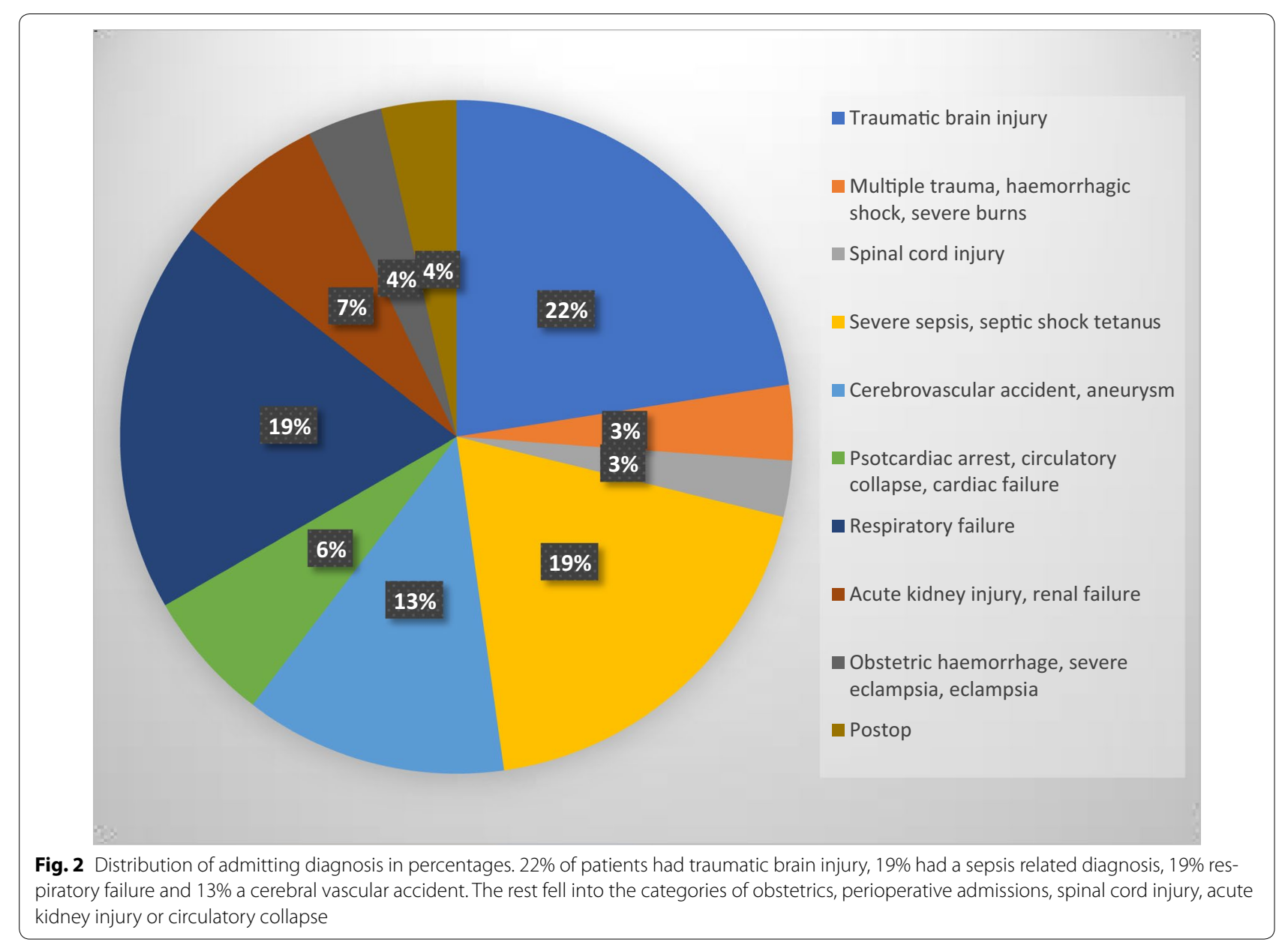


Table 2 Organisms isolated from samples taken off at admission to the ICU

\begin{tabular}{llll}
\hline Bacterial species & \multicolumn{2}{l}{ Sample } & \\
\cline { 2 - 4 } & Blood & Tracheal & Urine \\
& $\mathbf{N}=\mathbf{9 9}$ & $\mathbf{N}=\mathbf{6 7}$ & $\mathbf{N}=\mathbf{4}$ \\
& $\mathbf{N}(\%)$ & $\mathbf{N}(\%)$ & $\mathbf{N}$ (\%) \\
\hline Klebsiella pneumoniae & $1(1.00)$ & $8(11.94)$ & 0 \\
Staphylococcus aureus & $5(4.40)$ & $3(4.48)$ & 0 \\
Acinetobacter spp. & $1(1.00)$ & $4(5.97)$ & 0 \\
Pseudomonas aeruginosa & 0 & $3(4.48)$ & 0 \\
Enterobacter spp. & 0 & $2(2.99)$ & 0 \\
Escherichia coli & 0 & $5(7.46)$ & 0 \\
MRSA & 0 & 0 & 0 \\
Citrobacter freundi & $1(1.00)$ & 0 & 0 \\
Coagulase negative staphylococcus & $2(2.02)$ & $1(1.49)$ & 0 \\
Proteus mirabilis & 0 & $1(1.49)$ & 0 \\
Viridans streptococcus & 0 & 0 & 0 \\
Enterococcus spp. & 0 & 0 & 0
\end{tabular}

taken off. Generally, the highest susceptibility (Table 5; Fig. 3) rates were found to be to the amikacin, vancomycin and imipenem and the lowest rates were to cephalosporins, ciprofloxacin and gentamycin. Break down of susceptibility patterns according to sample is shown in Tables 5 and 6.

Twenty nine of the 52 isolates were MDR organisms. In Table 6, one isolate of Acinetobacter species was extensively drug resistant (XDR). Three isolates of $K$. pneumoniae and one of E. coli was extended spectrum beta lactamase (ESBL) producers while one isolate of K. pneumoniae was AmpC beta lactamase (AmpC BL) producer. There was only one isolate of MRSA.

Mechanical ventilation and traumatic brain injuries were highly associated with the risk of developing a nosocomial infection with values of 0.003 and 0.035 respectively. The age bracket $41-50$ years had an observed higher risk of infection odds ratio 0.27 (confidence interval $0.03-2.39$ ) and was statistically significant ( $\mathrm{p}$ value of 0.0412; Table 7).

\section{Discussion}

This is the first study of nosocomial bacterial infections in the ICU to be conducted in Uganda so there is no local data to compare with. Of 118 recruited patients, 111 were analysed and 50 isolates were obtained from 32 patients. Specimens were mainly from the blood stream and the trachea. Previous studies have documented that close to half of isolates in African ICUs are respiratory followed by abdominal and blood stream with urinary infections coming fourth [20]. This study was designed to collect bacterial isolates to study antimicrobial susceptibility patterns thus cannot be used to make the same conclusions.

Although studies have shown a trend towards greater proportion of Gram-positive infection, this study found the majority of isolates were Gram negative which supports findings from the extended prevalence of infection in intensive care (EPIC II) study [20].

This study found that the commonest Gram-negative organisms were $K$. pneumoniae, Acinetobacter species and $P$. aeruginosa while $S$. aureus was the commonest Gram-positive organism. This is in agreement with the EPIC II study in African ICUs especially the proportionately greater number of Acinetobacter species isolates [20]. Acinetobacter is known to be present in water supplies of hospitals [31], and contaminates resuscitation equipment and reusable ventilator circuits [32]. This suggests it can be prevented by simple infection control measures such sterilizing resuscitation equipment, reusable ventilator circuits and avoiding using tap water to flush nasogastric tube [20,32].

More than a quarter of $K$. pneumoniae isolates were ESBL producers, half of the E. coli isolates were AmpC beta lactamase producers and only one isolate was MRSA. This low rate of MRSA is unusual and is probably due to low proportion of samples from wounds and surgical sites as these are the sights commonly infected by MRSA [11].

Of the 52 isolates, only 1 isolate of Acinetobacter showed extensive drug resistance (XDR). A study on surgical site infection at Mulago National Hospital showed somewhat higher proportions of MDR and ESBL. However, this was in the obstetrics and gynaecology, general surgery and orthopaedic wards [33]. ICU rates are expected to be higher considering that it's a confluence of these wards. However, missed ICU opportunities are high and traumatic brain injuries (TBIs) take up a significant proportion of all admissions [34].

The highest susceptibility rates recorded for $K$. pneumoniae, $P$. aeruginosa and Acinetobacter species were to amikacin (with the exception of $P$. aeruginosa) and imipenem while the lowest susceptibility rates were to ampicillin, ceftriaxone, ceftazidime, ciprofloxacin and gentamicin. This is similar to findings in a study on antimicrobial resistance of Gram-negative bacilli among ICU patients in the USA [16]. However, a study in Kenyatta 


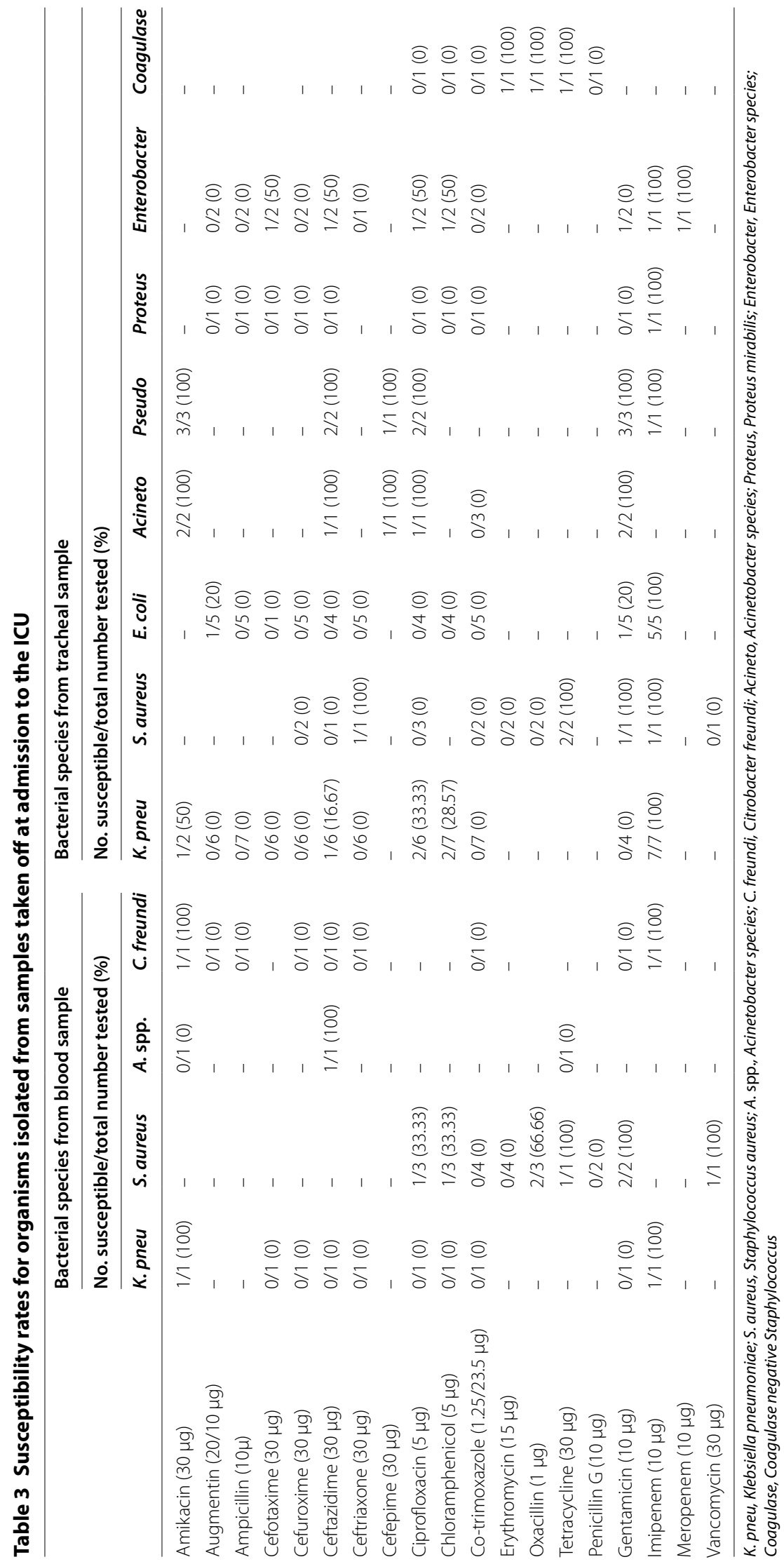


Table 4 Bacterial organism isolated from samples taken off after 48-72 $\mathrm{h}$ of admission

\begin{tabular}{|c|c|c|c|c|}
\hline \multirow[t]{4}{*}{ Bacterial species } & \multirow[t]{3}{*}{ No of isolates 52} & \multicolumn{3}{|l|}{ Sample } \\
\hline & & Blood & Tracheal & Urine \\
\hline & & $N=93$ & $N=59$ & $N=3$ \\
\hline & N (\%) & N (\%) & N (\%) & $\mathrm{N}(\%)$ \\
\hline Klebsiella pneumoniae & $15(28.8)$ & $2(2.15)$ & $13(22.03)$ & 0 \\
\hline Staphylococcus aureus & $7(13.5)$ & $3(3.23)$ & $4(6.78)$ & 0 \\
\hline Acinetobacter species & $11(21.2)$ & 0 & $11(18.64)$ & 0 \\
\hline $\begin{array}{l}\text { Pseudomonas aerugi- } \\
\text { nosa }\end{array}$ & $6(11.5)$ & $1(1.08)$ & $5(8.47)$ & 0 \\
\hline Enterobacter species & $5(9.6)$ & $1(1.08)$ & $4(6.78)$ & 0 \\
\hline Escherichia coli & $2(3.8)$ & $1(1.08)$ & $1(1.69)$ & 0 \\
\hline MRSA & $1(1.9)$ & $1(1.08)$ & 0 & 0 \\
\hline Citrobacter freundi & 0 & 0 & 0 & 0 \\
\hline $\begin{array}{l}\text { Coagulase negative } \\
\text { staphylococcus }\end{array}$ & $3(5.8)$ & $3(3.23)$ & 0 & 0 \\
\hline Proteus mirabilis & & 0 & 0 & 0 \\
\hline Viridans streptococcus & $1(1.9)$ & $1(1.08)$ & 0 & 0 \\
\hline Enterococcus species & $1(1.9)$ & $1(1.08)$ & 0 & 0 \\
\hline
\end{tabular}

national hospital found much better susceptibility to ceftazidime and this might be explained by a difference in prescribing practice [35]. The susceptibility rates to piperacillin and tazobactam were on average about $50 \%$, less than expected probably because of its increasing use [36]. The beta lactamase producers were susceptible to amikacin and imipenem. The available data show that carbapenems are the most active agents against ESBL Enterobacteriaceae however, the data for aminoglycosides is sparse and one review of 85 episodes of bacteraemia showed $71 \%$ of isolates were resistant to aminoglycosides [37, 38].

Staphylococcus aureus had the highest susceptibility to chloramphenicol, tetracycline and vancomycin while it was non-susceptible to cotrimoxazole, erythromycin, penicillin and oxacillin. The other Gram-positive isolates were all susceptible to vancomycin. MRSA was susceptible to amikacin, gentamicin and vancomycin. These findings are consistent with the study on surgical site wound infections in Mulago [33]. This may suggest that the organisms have a common origin. A study by Seni et al. to characterise the lineages of $S$. aureus among patients with surgical site infection at Mulago found two predominate lineages clonally circulating on the surgical wards and three others confined to the obstetric wards [39]. So, it is plausible that the patterns of susceptibility seen in the ICU maybe do to single clones.
This study found an association between ventilation and development of an NI 48-72 h after admission. A patient was more likely to develop a NI if they were given ventilator support odds ratio 4.43 and was statistically significant ( $\mathrm{p}$ value of 0.002 ). This is not surprising as ventilator support was invasive and is similar to findings in a number of studies all over the world [20,40]. There is a relationship between severe traumatic brain injury and development of a nosocomial infection odds ratio 3.05 and $p$ value 0.03 . These patients were usually intubated and on mechanical ventilation. In addition, the age bracket 41-50 years had an observed higher risk of infection odds ratio 0.27 (confidence interval 0.03-2.39) and was statistically significant ( $\mathrm{p}$ value of 0.0412 ). The risk of infection is greater with advanced age especially over the age of 60 and this is because of impaired immune system with extremes of age [41, 42]. However, in this study there was no observed increase in risk of infection with patients above 60 years.

\section{Limitations}

We excluded patients under 18 years who would have made a significant contribution to the study population.

The majority of patients, $72 \%$, were on antibiotics prior to admission and its plausible that the prevalence of bacteria seen is not an accurate estimate of the truth. The chances of identifying bacteria are greater when samples are taken off before antibiotics are given. We however, found there was an increased risk of infection in these patients that didn't reach statistical significance (Table 7).

\section{Conclusion}

The findings suggest that the commonest bacterial NI are K. pneumoniae, Acinetobacter species, S. aureus, P. aeruginosa, Enterobacter species, coagulase negative Staphylococcus, E. coli and Enterococcus species. The prevalence of MDR bacterial species was $58.0 \%$ with $50 \%$ of $E$. coli and $33.3 \%$ of $K$. pneumoniae ESBL or AmpC BL producers and $9.1 \%$ of Acinetobacter species XDR. Imipenem and amikacin are the antibiotics with the highest susceptibility rates across most bacterial species. Institution of ventilatory support and severe traumatic brain injury are associated with increased risk for the development of NI.

The increased rates of Acinetobacter in our ICUs compared to ICUs in Europe and North America are an indication of difference in practice and mean simple change in practice such as sterilization of ambu bags and breathing circuits can reduce the rates of this infection. There is a need for increased funding for healthcare and stricter policies on infection control practices such as hand 


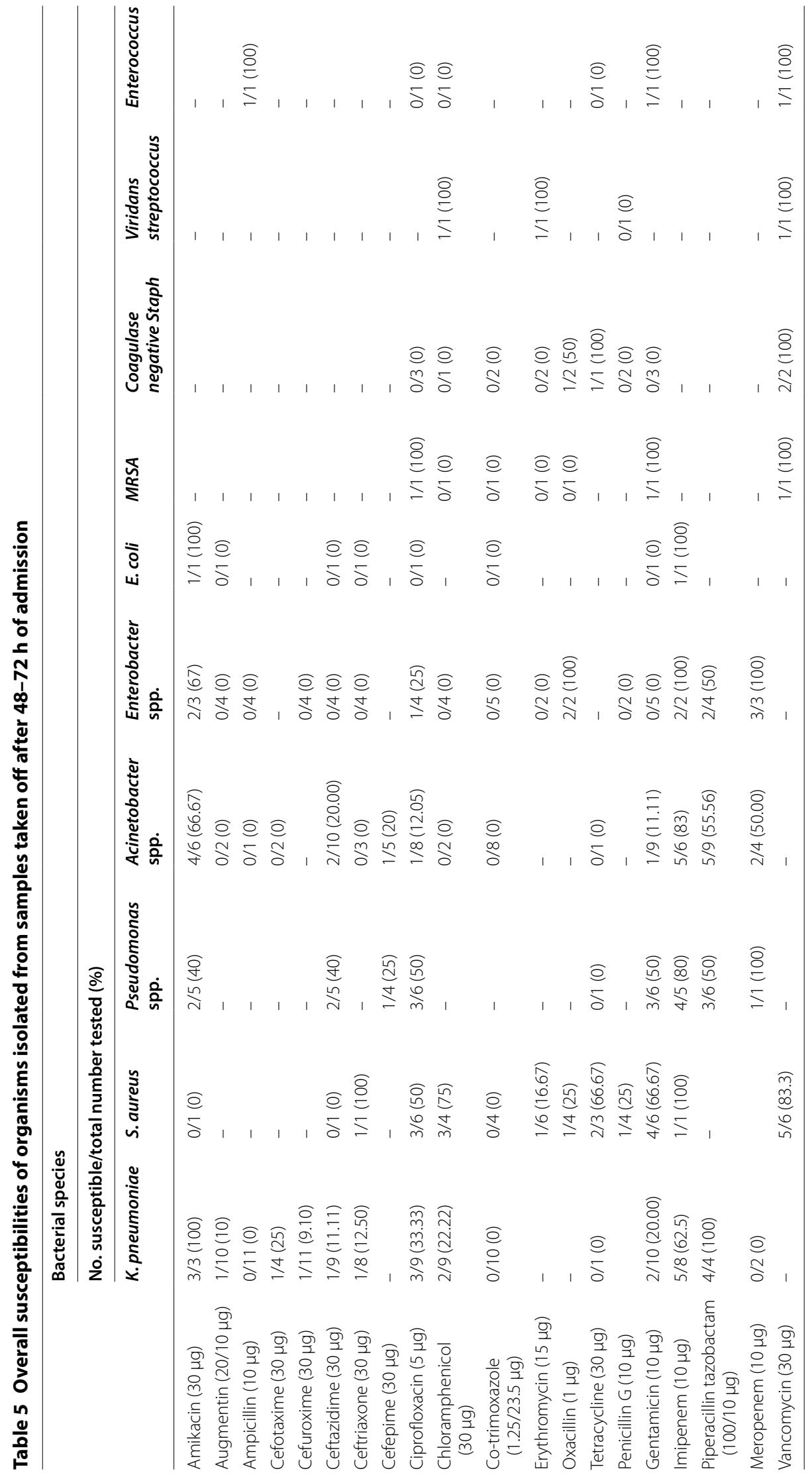




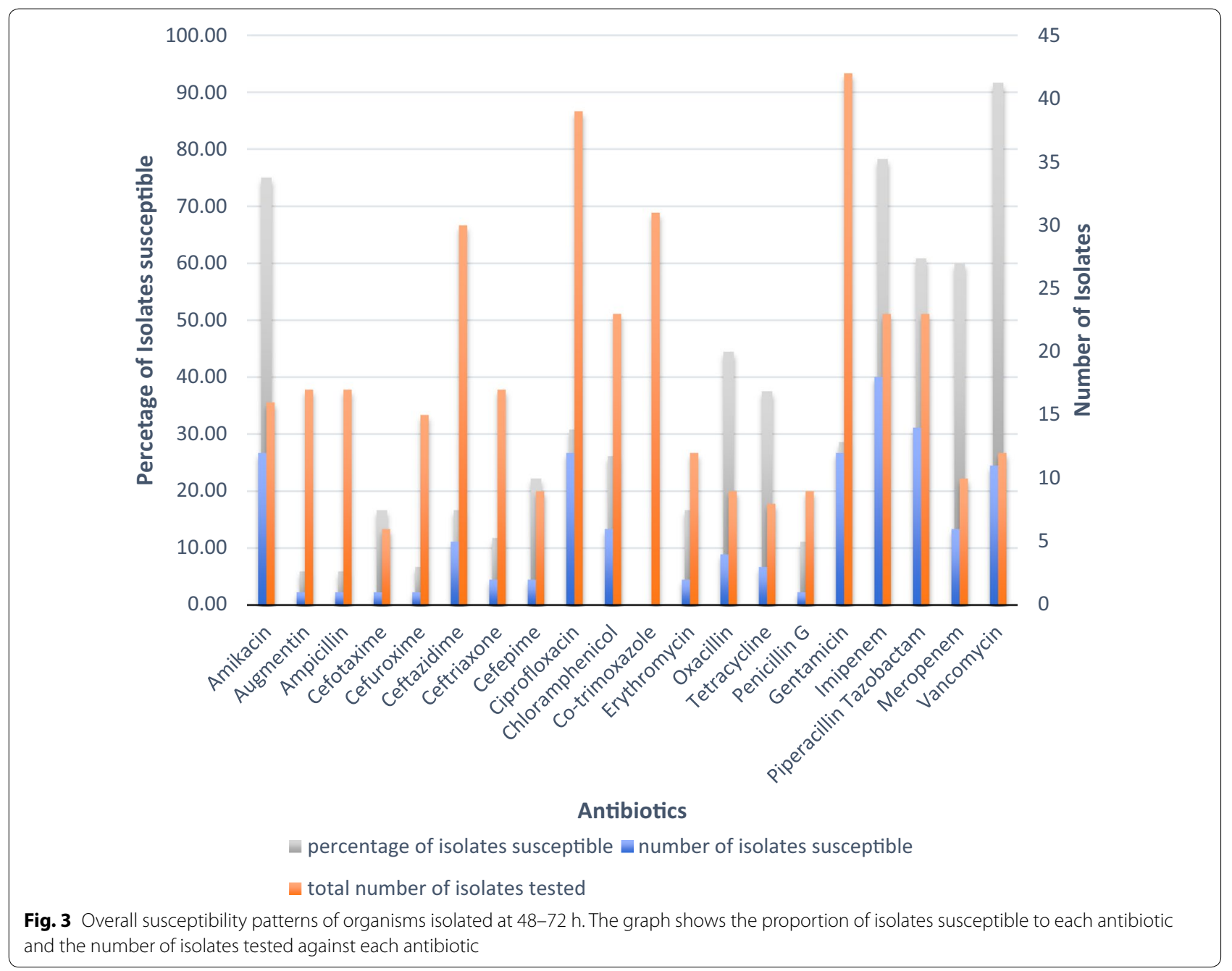

Table 6 Multidrug resistant organism isolated after 48-72 h in the ICU

\begin{tabular}{lll}
\hline Organism & $\begin{array}{l}\text { No. of MDR isolates/ } \\
\text { total no. of isolates }\end{array}$ & $\begin{array}{l}\text { \% of isolates } \\
\text { that were MDR }\end{array}$ \\
\hline Klebsiella pneumoniae & $11 / 15$ & 73.3 \\
Acinetobacter species & $7 / 11$ & 63.6 \\
P. aeruginosa & $3 / 6$ & 50.0 \\
Staphylococcus aureus & $4 / 7$ & 57.1 \\
Enterobacter species & $3 / 5$ & 60.0 \\
Escherichia coli & $1 / 2$ & 50.0 \\
Overall & $29 / 50$ & 58.0 \\
\hline
\end{tabular}

washing and infection control bundles. The difference in infection rates across ICUs in the country should be investigated and an audit of infection control practices should be carried out.

The prescription of carbapenems should be restricted to initial management of serious bacterial infection in which MDR organism are suspected and should be avoided in situations were a narrow spectrum antibiotic would be equally effective. Antibiograms in the ICU are needed to assess local susceptibility patterns and aid in selecting empiric antibiotic therapy and in monitoring resistance trends in the hospital. There is a need for 
Table 7 Associated factors for infection after $48 \mathrm{~h}$ of admission in the ICU

\begin{tabular}{|c|c|c|c|c|}
\hline Risk factors & $\begin{array}{l}\text { Not infected } \\
\mathrm{N}(\%)\end{array}$ & $\begin{array}{l}\text { Infected } \\
\mathrm{N}(\%)\end{array}$ & $\begin{array}{l}\text { Odds ratio } \\
(95 \% \mathrm{Cl})\end{array}$ & $P$ value \\
\hline \multicolumn{5}{|l|}{ Age group in years } \\
\hline$\leq 30$ & $30(37.97)$ & $14(43.75)$ & $1.27(0.55-2.92)$ & 0.723 \\
\hline $31-40$ & $18(22.78)$ & $8(25.00)$ & $1.13(0.43-2.94)$ & 0.983 \\
\hline $41-50$ & $8(9.86)$ & $1(3.13)$ & $0.27(0.03-2.39)$ & 0.0412 \\
\hline $51-60$ & $10(10.13)$ & $3(9.38)$ & $0.71(0.18-2.78)$ & 0.901 \\
\hline$>60$ & $13(16.46)$ & $6(18.75)$ & $1.17(0.40-3.41)$ & 0.969 \\
\hline \multicolumn{5}{|l|}{ Sex } \\
\hline Female & $34(43.04)$ & $15(46.88)$ & & \\
\hline Male & $45(56.96)$ & $17(53.13)$ & $0.86(0.38-1.95)$ & 0.717 \\
\hline \multicolumn{5}{|c|}{ Referring within hospital } \\
\hline No & $12(15.19)$ & $5(15.63)$ & & \\
\hline Yes & $67(84.81)$ & $27(84.38)$ & $0.97(0.31-3.01)$ & 0.935 \\
\hline \multicolumn{5}{|c|}{ Admitting diagnosis } \\
\hline $\begin{array}{l}\text { Traumatic brain } \\
\text { injury }\end{array}$ & $13(16.46)$ & $12(37.50)$ & $3.05(1.20-7.72)$ & 0.035 \\
\hline Haemorrhage & $2(2.53)$ & $2(6.25)$ & $2.57(0.35-19.05)$ & 0.653 \\
\hline $\begin{array}{l}\text { Spinal cord } \\
\text { injury }\end{array}$ & $2(2.53)$ & $1(3.13)$ & $\begin{array}{l}1.242(0.11- \\
14.20)\end{array}$ & 0.843 \\
\hline Severe sepsis & $18(22.78)$ & $3(9.38)$ & $0.35(0.10-1.29)$ & 0.163 \\
\hline $\begin{array}{c}\text { Cerebrovascu- } \\
\text { lar accident }\end{array}$ & $9(11.39)$ & $5(15.63)$ & $1.44(0.44-4.69)$ & 0.747 \\
\hline $\begin{array}{l}\text { Cardiac condi- } \\
\text { tion }\end{array}$ & $7(8.86)$ & 0 & - & - \\
\hline $\begin{array}{r}\text { Respiratory } \\
\text { condition }\end{array}$ & $18(22.78)$ & $3(9.38)$ & $0.35(0.10-1.29)$ & 0.163 \\
\hline $\begin{array}{l}\text { Kidney condi- } \\
\text { tion }\end{array}$ & $5(6.33)$ & $3(9.38)$ & $1.53(0.34-6.82)$ & 0.837 \\
\hline $\begin{array}{l}\text { Obstetric } \\
\text { condition }\end{array}$ & $1(1.27)$ & $3(9.38)$ & $8.07(0.81-80.71)$ & 0.143 \\
\hline Post Operative & $4(5.06)$ & 0 & - & - \\
\hline \multicolumn{5}{|c|}{ Antibiotics before admission } \\
\hline No & $18(22.78)$ & $4(12.50)$ & & \\
\hline Yes & $61(77.22)$ & $28(87.50)$ & $2.07(0.64-6.67)$ & 0.334 \\
\hline \multicolumn{5}{|l|}{ Ventilation } \\
\hline No & $43(54.43)$ & $7(21.88)$ & & \\
\hline Yes & $36(45.57)$ & $25(78.13)$ & $4.27(1.65-11.01)$ & 0.003 \\
\hline
\end{tabular}

development of strong policies on antibiotic stewardship, antimicrobial surveillance and infection control to prevent the spread of MDR bacteria and antibiotic drug resistance.

\section{Additional file}

Additional file 1. Questionnaire: This is a copy of the questionnaire used throughout the study to collect data.

\section{Abbreviations}

HAl: hospital acquired infection; NI: nosocomial infection; ICU: intensive care unit; USA: United States of America; MRSA: methicillin resistant Staphylococcus aureus; MDR: multidrug resistant; XDR: extensively drug resistant; ESBL: extended spectrum beta lactamase; BL: beta lactamase; WHO: World Health Organization; CLSI: Clinical and Laboratory Standards Institute; CVA: cerebral vascular accident; AKl: acute kidney injury; Clinically significant sample: samples from the site or suspected site of infection for example a tracheal aspirate in a case of ventilator associated pneumonia; Nosocomial infection: hospital acquired infection developing at least $48 \mathrm{~h}$ after admission.

\section{Authors' contributions}

PA, AK, and JVBT wrote the concept; PA collected the data; JT, PA, and AK wrote the manuscript. All authors read and approved the final manuscript.

\section{Acknowledgements}

We thank Dr. Nodreen Ayupo, Dr. Ezra Mugisha and Dr. Paul Musinga for their assistance in data collection. We thank Mr. Hannington Baluku Tasimwa from the department of medical microbiology school of medicine Makerere University for all his help.

Competing interests

The authors declare that they have no competing interests.

\section{Availability of data and materials}

The datasets used during the current study are available from the corresponding author on reasonable request.

\section{Consent to publish \\ Not applicable.}

\section{Ethical considerations}

Ethical approval was obtained on the 27th of May 2013 from the ethical board of the college of health sciences Makerere University (Chaired by Professor James Tumwine). A waiver to participate was also obtained from the ethics committee.

\section{Funding}

The study was self-funded.

\section{Publisher's Note}

Springer Nature remains neutral with regard to jurisdictional claims in published maps and institutional affiliations.

Received: 3 February 2017 Accepted: 26 July 2017

Published online: 28 July 2017

\section{References}

1. Vincent J. Nosocomial infections in adult intensive-care units. Lancet. 2003;361 (9374):2068-77.

2. Erlandsson $\mathrm{CM}$, Hanberger $\mathrm{H}$, Eliasson I, Hoffmann M, Isaksson B, Lindgren $\mathrm{S}$, et al. Surveillance of antibiotic resistance in ICUs in southeastern Sweden. ICU Study Group of the South East of Sweden. Acta Anaesthesiol Scand. 1999;43(8):815-20

3. Asensio A, Oliver A, Gonzalez-Diego P, Baquero F, Perez-Diaz JC, Ros P, et al. Outbreak of a multiresistant Klebsiella pneumoniae strain in an intensive care unit: antibiotic use as risk factor for colonization and infection. Clin Infect Dis. 2000;30(1):55-60

4. Richards MJ, Edwards JR, Culver DH, Gaynes RP. Nosocomial infections in combined medical-surgical intensive care units in the United States. Infect Control Hosp Epidemiol. 2000;21(8):510-5.

5. Trilla A. Epidemiology of nosocomial infections in adult intensive care units. Intensive Care Med. 1994;20(Suppl 3):S1-4.

6. Eggimann P, Pittet D. Infection control in the ICU. Chest. 2001;120(6):2059-93. 
7. Brasme L, Nordmann P, Fidel F, Lartigue MF, Bajolet O, Poirel L, et al. Incidence of class A extended-spectrum beta-lactamases in ChampagneArdenne (France): a 1 year prospective study. J Antimicrob Chemother. 2007;60(5):956-64.

8. Chambers HF. Community-associated MRSA-resistance and virulence converge. N Engl J Med. 2005;352(14):1485-7.

9. Weinstein RA. Nosocomial infection update. Emerg Infect Dis. 1998;4(3):416-20.

10. Jarvis WR. Infection control and changing health-care delivery systems. Emerg Infect Dis. 2001;7(2):170-3.

11. Zhanel GG, DeCorby M, Laing N, Weshnoweski B, Vashisht R, Tailor F, et al. Antimicrobial-resistant pathogens in intensive care units in Canada: results of the Canadian National Intensive Care Unit (CAN-ICU) study, 2005-2006. Antimicrob Agents Chemother. 2008;52(4):1430-7.

12. Ojulong J, Mwambu TP, Joloba M, Bwanga F, Kaddu-Mulindwa DH. Relative prevalence of methicilline resistant Staphylococcus aureus and its susceptibility pattern in Mulago Hospital, Kampala, Uganda. Tanzan J Health Res. 2009;11(3):149-53.

13. Boyce JM. Are the epidemiology and microbiology of methicillin-resistant Staphylococcus aureus changing? JAMA. 1998;279(8):623-4.

14. Kesah C, Ben Redjeb S, Odugbemi TO, Boye CS, Dosso M, Ndinya Achola $\mathrm{JO}$, et al. Prevalence of methicillin-resistant Staphylococcus aureus in eight African hospitals and Malta. Clin Microbiol Infect. 2003;9(2):153-6.

15. Morgan GE, Mikhail MS, Murray MJ. Critical care. Clinical anesthesiology. 4th ed. New York: McGraw-Hill Companies, Inc; 2006. p. 1050-1.

16. Lockhart SR, Abramson MA, Beekmann SE, Gallagher G, Riedel S, Diekema DJ, et al. Antimicrobial resistance among Gram-negative bacilli causing infections in intensive care unit patients in the United States between 1993 and 2004. J Clin Microbiol. 2007:45(10):3352-9.

17. American Thoracic S, Infectious Diseases Society of A. Guidelines for the management of adults with hospital-acquired, ventilator-associated, and healthcare-associated pneumonia. Am J Respir Crit Care Med. 2005:171(4):388-416.

18. Coffin SE, Klompas M, Classen D, Arias KM, Podgorny K, Anderson DJ, et al. Strategies to prevent ventilator-associated pneumonia in acute care hospitals. Infect Control Hosp Epidemiol. 2008;29(Suppl 1):S31-40.

19. De Waele JJ, Ravyts M, Depuydt P, Blot SI, Decruyenaere J, Vogelaers D. De-escalation after empirical meropenem treatment in the intensive care unit: fiction or reality? J Crit Care. 2010;25(4):641-6.

20. Vincent JL, Rello J, Marshall J, Silva E, Anzueto A, Martin CD, et al. International study of the prevalence and outcomes of infection in intensive care units. JAMA. 2009:302(21):2323-9.

21. Allegranzi B, Nejad SB, Combescure C, Graafmans W, Attar H, Donald-

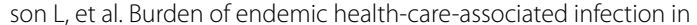
developing countries: systematic review and meta-analysis. Lancet. 2011;377(9761):228-41.

22. Burgmann H, Hiesmayr JM, Savey A, Bauer P, Metnitz B, Metnitz PG. Impact of nosocomial infections on clinical outcome and resource consumption in critically ill patients. Intensive Care Med. 2010;36(9):1597-601.

23. Kelsey MC. The management and control of hospital-acquired infection in acute NHS trusts in England: a report by the Comptroller and Auditor General — the who, how and what. J Hosp Infect. 2000;44(3):157-9.

24. Zhanel GG, DeCorby M, Adam H, Mulvey MR, McCracken M, LagaceWiens $\mathrm{P}$, et al. Prevalence of antimicrobial-resistant pathogens in Canadian hospitals: results of the Canadian Ward Surveillance Study (CANWARD 2008). Antimicrob Agents Chemother. 2010;54(11):4684-93.

25. Haley RW, Culver DH, White JW, Morgan WM, Emori TG, Munn VP, et al. The efficacy of infection surveillance and control programs in preventing nosocomial infections in US hospitals. Am J Epidemiol. 1985;121(2):182-205.

26. McNeil SA, Foster CL, Hedderwick SA, Kauffman CA. Effect of hand cleansing with antimicrobial soap or alcohol-based gel on microbial colonization of artificial fingernails worn by health care workers. Clin Infect Dis. 2001;32(3):367-72.

27. Allegranzi B, Pittet D. Role of hand hygiene in healthcare-associated infection prevention. J Hosp Infect. 2009;73(4):305-15.

28. Blot S. Limiting the attributable mortality of nosocomial infection and multidrug resistance in intensive care units. Clin Microbiol Infect. 2008;14(1):5-13.
29. Anguzu JR, Olila D. Drug sensitivity patterns of bacterial isolates from septic post-operative wounds in a regional referral hospital in Uganda. Afr Health Sci. 2007;7(3):148-54

30. Magiorakos AP, Srinivasan A, Carey RB, Carmeli Y, Falagas ME, Giske CG, et al. Multidrug-resistant, extensively drug-resistant and pandrug-resistant bacteria: an international expert proposal for interim standard definitions for acquired resistance. Clin Microbiol Infect. 2012;18(3):268-81.

31. Yaslianifard S, Mobarez AM, Fatolahzadeh B, Feizabadi MM. Colonization of hospital water systems by Legionella pneumophila, Pseudomonas aeroginosa, and Acinetobacter in ICU wards of Tehran hospitals. Indian J Pathol Microbiol. 2012;55(3):352-6.

32. Hartstein Al, Rashad AL, Liebler JM, Actis LA, Freeman J, Rourke JW Jr, et al. Multiple intensive care unit outbreak of Acinetobacter calcoaceticus subspecies anitratus respiratory infection and colonization associated with contaminated, reusable ventilator circuits and resuscitation bags. Am J Med. 1988;85(5):624-31.

33. Seni J, Najjuka CF, Kateete DP, Makobore P, Joloba ML, Kajumbula H, et al. Antimicrobial resistance in hospitalized surgical patients: a silently emerging public health concern in Uganda. BMC Res Notes. 2013;6:298.

34. Mpumwire SP. Prevalence of missed critical care opportunities; associated factors and 72 hour mortality in adult patients admitted at Mulago Hospital Emergency Ward; 2012. http://hdl.handle.net/10570/2986. Accessed 10 Dec 2014.

35. Ngumi ZW. Nosocomial infections at Kenyatta National Hospital Intensive-Care Unit in Nairobi, Kenya. Dermatology. 2006;212(Suppl 1):4-7.

36. Lee J, Oh CE, Choi EH, Lee HJ. The impact of the increased use of piperacillin/tazobactam on the selection of antibiotic resistance among invasive Escherichia coli and Klebsiella pneumoniae isolates. Int J Infect Dis. 2013;17(8):e638-43.

37. Paterson DL, Ko WC, Von Gottberg A, Mohapatra S, Casellas JM, Goossens $\mathrm{H}$, et al. Antibiotic therapy for Klebsiella pneumoniae bacteremia: implications of production of extended-spectrum beta-lactamases. Clin Infect Dis. 2004;39(1):31-7.

38. Endimiani A, Luzzaro F, Perilli M, Lombardi G, Coli A, Tamborini A, et al. Bacteremia due to Klebsiella pneumoniae isolates producing the TEM-52 extended-spectrum beta-lactamase: treatment outcome of patients receiving imipenem or ciprofloxacin. Clin Infect Dis. 2004;38(2):243-51.

39. Seni J, Bwanga F, Najjuka CF, Makobore P, Okee M, Mshana SE, et al. Molecular characterization of Staphylococcus aureus from patients with surgical site infections at Mulago Hospital in Kampala, Uganda. PLoS ONE. 2013;8(6):e66153.

40. Nourdine K, Combes P, Carton MJ, Beuret P, Cannamela A, Ducreux JC. Does noninvasive ventilation reduce the ICU nosocomial infection risk? A prospective clinical survey. Intensive Care Med. 1999;25(6):567-73.

41. Ben-Ami R, Rodriguez-Bano J, Arslan H, Pitout JD, Quentin C, Calbo ES, et al. A multinational survey of risk factors for infection with extendedspectrum beta-lactamase-producing enterobacteriaceae in nonhospitalized patients. Clin Infect Dis. 2009;49(5):682-90.

42. Safdar N, Maki DG. The commonality of risk factors for nosocomial colonization and infection with antimicrobial-resistant Staphylococcus aureus, enterococcus, gram-negative bacilli, Clostridium difficile, and Candida. Ann Intern Med. 2002;136(11):834-44.

\section{Submit your next manuscript to BioMed Central and we will help you at every step:}

- We accept pre-submission inquiries

- Our selector tool helps you to find the most relevant journal

- We provide round the clock customer support

- Convenient online submission

- Thorough peer review

- Inclusion in PubMed and all major indexing services

- Maximum visibility for your research

Submit your manuscript at www.biomedcentral.com/submit 